\title{
Tras la imagen del Santiago turístico*
}

\author{
TOMÁS ERRÁZURIZ** \\ ** Candidato a Doctor en Arquitectura y Estudios Urbanos, Pontificia Universidad Católica de Chile
}

\section{Introducción}

El creciente desarrollo de la actividad turística a nivel mundial y la consolidación de las ciudades como uno de los destinos turísticos por excelencia y como centros organizadores de esta actividad han generado una producción significativa de representaciones e imágenes con fines de promoción y difusión turística de distintas ciudades y sus territorios aledaños. Estas representaciones, a diferencia de otras formas más tradicionales elaboradas desde campos como el urbanismo, la geografía, la arquitectura o la historia, implican nuevas formas de conocimiento y aproximación a lo urbano.

En este contexto, Chile ha mostrado altas tasas de crecimiento en el rubro turístico durante los últimos ańos, siendo Santiago la ciudad que concentra la mayor cantidad de visitas de extranjeros. En consecuencia, se ha generado un abundante material gráfico en donde se representa a la ciudad y sus alrededores, que circula entre los turistas como instrumento fundamental de conocimiento de la ciudad.

El presente artículo se pregunta por las características que revisten estas imágenes de ciudad, concentrándose tanto en las implicancias de los medios gráficos utilizados la definición del encuadre o límites de lo representado, hasta aquellos aspectos relacionados directamente con los elementos contenidos en la imagen. Se propone la existencia de una amplia confluencia entre los intereses públicos y privados en la imagen de Santiago que se busca difundir al turista extranjero. Esta imagen tiene como característica distintiva la demarcación de una "ciudad turística" que se construye en base al encuentro de una pequeña escala barrial de condiciones ideales con la gran escala regional; y el ocultamiento de una ciudad no turística, constituida por todo el espacio urbano que conforma los extensos polígonos intersticiales que en la ciudad real separan estas dos polos de interés turístico.

Se ha revisado el material gráfico producido con fines turísticos (folletos, planos, mapas y guías) que se entrega a los visitantes que solicitan información turística sobre Santiago y sus alrededores en las oficinas del Servicio Nacional de Turismo, en la Municipalidad de Santiago y Providencia y en algunos de los principales hoteles de cuatro y cinco estrellas de la capital.

\footnotetext{
* Una versión preliminar de este artículo titulada "Behind the tourist images of the city: winners and losers in Santiago of Chile's urban space" fue presentada en el congreso "Tourism Visuality". 12-15 de junio, 2007, University of Brighton, Inglaterra.

Correspondencia: Tomás Errázuriz, El Comendador 1970, Providencia, Santiago, Chile. E-mail: terrazur@uc.cl
} 


\section{Industria del turismo, turistas y ciudades turísticas}

Algunos han catalogado al siglo XX como el siglo del turismo, argumentando que los habitantes del mundo sólo en estas dos últimas décadas han conocido más gente que en cualquier otro minuto de la historia. Según las predicciones para la industria del turismo, este rubro debiera crecer durante los siguientes años a un acelerado ritmo del $4 \%$ anual, alcanzando para el 2010 un billón de llegadas internacionales y más de US\$ 2400 billones en ingresos al año (AlSayyad, 2001).

El turismo es una actividad relativamente reciente que se remonta a la segunda mitad del siglo XIX, cuando Thomas Cook implementó los primeros paquetes turísticos para recorrer el continente europeo, considerando en sus recorridos sitios históricos e importantes atractivos culturales, haciéndose cargo del alojamiento y entregando información y asistencias de primera necesidad (Judd, 2003). En este sentido, se podría afirmar que el turismo surge como una actividad, en la medida en que aparece una industria turística que se hace cargo de la necesidad de viajar y visitar diversos destinos.

En este entendido, el turista vendría siendo aquel a quien dirige su oferta la industria turística. En contraposición a lo que sería un viajero o un expedicionario "el turista es aquel que por excelencia se confunde en un 'tipo', y no aspira a ser un 'arquetipo', es decir, no aspira a ser un modelo de individualidad” (Fermandois, 2000, p. 344). Concebir al turista como alguien que se confunde con un "tipo" es pensar en él como un consumidor que ha sido estudiado y clasificado por una industria que elabora y ofrece una cadena de productos diferenciados acorde a las condiciones específicas que esta persona demanda.

Si bien el turismo tuvo su origen en una entidad privada, el rápido crecimiento del rubro y las múltiples repercusiones de la actividad en el desarrollo económico de ciudades y naciones significó que desde temprano fuese incorporado a la agenda pública por gobiernos centrales y municipales. Hoy en día, la industria turística debe ser comprendida como un ámbito de acción donde se encuentran, con distinta fortuna según cada caso, intereses privados y públicos.

Las grandes ciudades y capitales nacionales cumplen un papel fundamental en el desarrollo de la industria turística. Por una parte se han posicionado como un potencial destino de interés turístico, debido a la diversidad de experiencias que pueden ofrecer a sus visitantes y a las posibilidades de investir un soporte físico-construido con valores patrimoniales u otras significaciones que puedan posteriormente ser vendidas; mientras por otra parte estas ciudades son, bajo una lógica de la globalización, los nódulos visibles de una red mundial de movimiento de capitales, los centros culturales y políticos por excelencia y una zona de influencia y acceso sobre el territorio aledaño y los asentamientos menores.

Esta centralidad deriva en campañas promocionales, construcción de material de difusión y estrategias publicitarias que posicionan a una ciudad, y su sistema de posibilidades circundantes como atractivo turístico frente a otras ciudades y sus regiones aledańas. En consecuencia, la gran mayoría de las ciudades genera, ya sea desde organismos privados, públicos o en instancias de 
colaboración, múltiples representaciones en torno a la ciudad y a sus potencialidades turísticas. Mapas, planos, guías, fotografías, infografías, ilustraciones, logotipos, etc. constituyen la base de este material e implican la construcción de diversas imágenes de la ciudad legitimadas y promovidas desde la industria del turismo.

De esta manera, comúnmente el turista se enfrenta a una ciudad que ha sido previamente demarcada, resignificada y acotada, donde se han fijado los recorridos y los lugares de interés, tradicionales y alternativos. En forma de folletos, guías turísticas y planos, esta información se presenta como conocimiento apriorístico y verdadero de las ciudades y territorios reseńados. Se favorece una cosificación de lo urbano, su presentación como un objeto medible, nítidamente definido y compuesto por múltiples partes diferentes entre sí; como un paradigma de conocimiento cartesiano de indubitabilidad, claridad y distinción. Esta definición de un discurso descriptivo, catalogador, unívoco y autoritario, para los diversos recorridos y actividades propuestas, es sintomático y coherente con los fines comerciales y utilitarios que rigen la promoción turística de un lugar.

Sin embargo, no se deben confundir las imágenes de la ciudad promovidas desde el turismo y la imagen de ciudad que finalmente se forma el turista de los sitios visitados, que si bien está fuertemente influida por las primeras, nunca es producto de un traspaso directo, sino que implica una inevitable interpretación dada por la irrepetibilidad de la experiencia particular.

\section{Santiago de Chile}

En Chile la actividad turística se ha incrementado notoriamente durante la última década, transformándose en uno de los cinco rubros económicos principales del país luego del cobre, el sector frutícola, la producción forestal, los salmones y la celulosa (Sernatur, 2006). Durante los últimos cuatro ańos la actividad turística ha crecido por sobre el 10\% anual, lo que se tradujo durante el año 2006 en la entrada a territorio nacional de 2,25 millones de turistas extranjeros, quienes dejaron ingresos que superan los 500 millones de dólares (La Segunda, 2006).

Un estudio realizado por el Sernatur sobre el perfil del turista en Chile muestra que Santiago y sus alrededores son el lugar más visitado por los turistas extranjeros, concentrando un 47,8\% de los destinos, seguido por Viña del Mar, Valparaíso y Reñaca con un 32,3\% (Sernatur, 2001). Este liderazgo de la capital y sus zonas aledañas en el ranking de los destinos turísticos ha motivado un crecimiento de la oferta de servicios turísticos en diversos ámbitos tales como el gastronómico, el hotelero, los recorridos guiados, los deportes de excursión y recreación, la actividad comercial, los espacios de exhibición, etc., así como un desarrollo, diversificación y ampliación de las instituciones involucradas en esta actividad.

Por su parte, esta ampliación de la oferta, conlleva necesariamente la generación de abundante material de difusión y promoción de lo ofertado. El Servicio Nacional de Turismo y los hoteles son los principales distribuidores de este material que tiene como primeros destinatarios al turismo receptor proveniente de Europa y Estados Unidos, que suman en total un 52,9\% de los ingresos económicos que genera esta actividad en Chile y constituyen sólo un 30,2\% de los turistas que recibe el país. En cambio, el 51,1\% de los turistas extranjeros visitantes 
Figura 1. Plano turístico de Santiago "Santiago Alive".

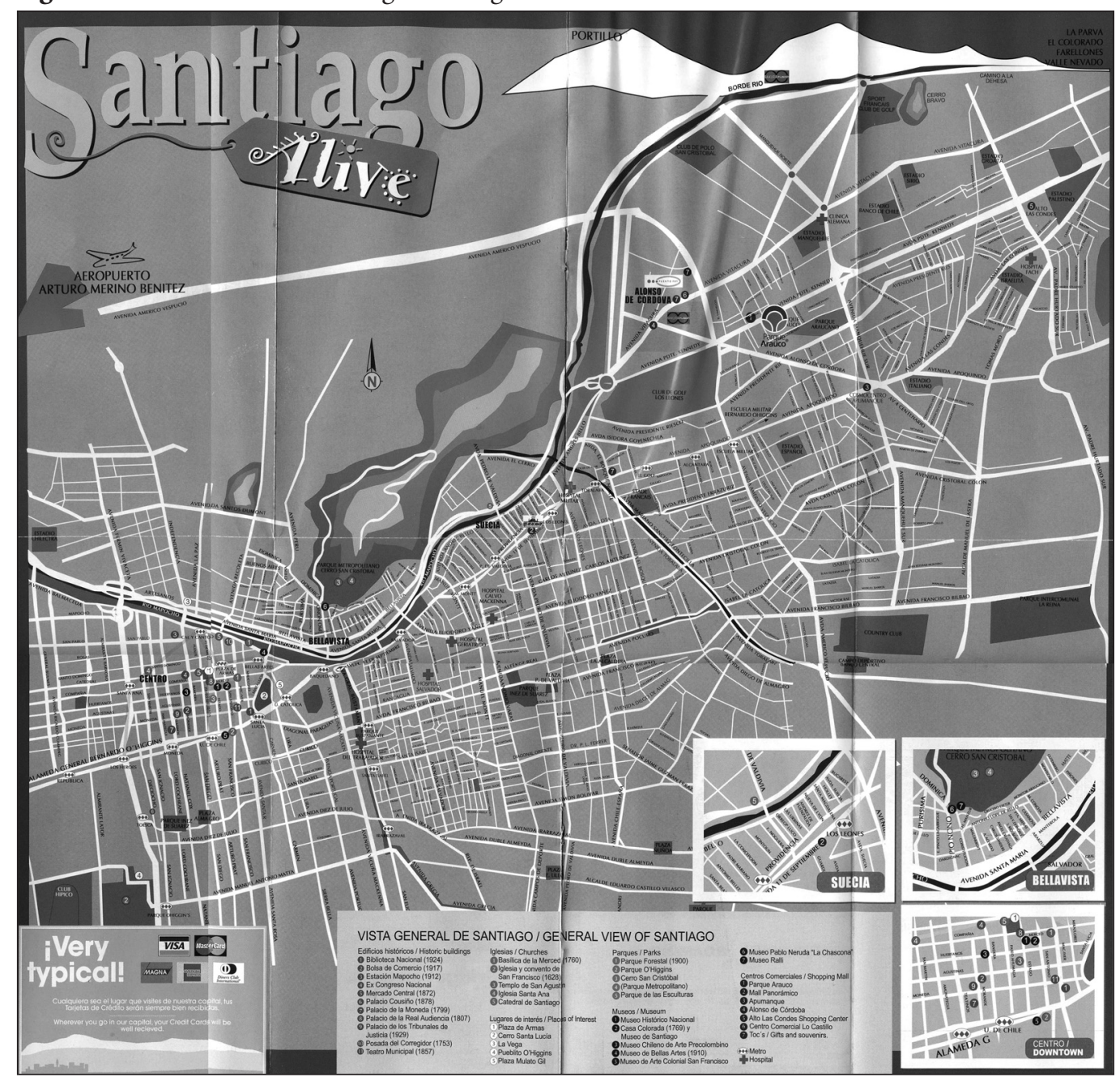

Fuente: Contenido al interior de la guía de reparto gratuito "Santiago Alive", publicación producida por Imagen Turística S. A., número 17, julio de 2005 (circulación: 4 ediciones anuales).

proviene de los países limítrofes y apenas representa el 21,9\% ingresos que se perciben en el rubro (Sernatur, 2006).

Los mapas y fotografías de la ciudad son los medios predilectos en que esta se representa, distribuidos al visitante con el fin de orientar y significar su experiencia de consumo y ocio. En este sentido, su análisis resulta de gran utilidad para identificar la imagen de ciudad que se busca vincular a esta actividad y los fines que persigue la industria del turismo mediante esta representación. La pregunta ¿Cómo es la imagen de Santiago que se intenta legitimar y difundir desde la industria turística? Que se abordará en las siguientes líneas, deberá responderse necesariamente desde otras preguntas como ¿Qué es lo que se representa en estas imágenes de ciudad y qué queda excluido de ellas? ¿Qué medios gráficos son los más utilizados y cuales son sus implicancias sobre la construcción de imágenes? ¿ ¿Qué aspectos se resaltan y cuales son subvalorados? 


\section{Santiago turístico}

Lo primero que llama la atención cuando observamos los planos turísticos de la ciudad de Santiago es que en ellos no aparece la ciudad de Santiago que acostumbramos ver en los mapas geográficos o fotos aéreas. Aunque la ciudad representada es sólo un fragmento del total, ésta se presenta generalmente como el total de la ciudad. A la ciudad fundacional (downtown) se anexa el cono de alta renta: Providencia, Vitacura, Las Condes, La Reina (a veces algo de Nuñoa o Huechuraba), mientras se omiten deliberadamente las circunscripciones restantes.

El polígono seleccionado funciona como una unidad urbana autónoma que desconoce la existencia del resto de la ciudad donde se emplaza. Esta ficción se consigue, en primer lugar, mediante la alteración del tamaño de las manzanas que conforman la trama urbana más allá del espacio de interés turístico, extendiendo las dimensiones de los predios hasta simular una condición de ruralidad, en la realidad inexistente. Una segunda estrategia gráfica consiste en sobredimensionar los elementos geográficos hasta que constituyan verdaderas barreras o límites urbanos. Por último, también la diagramación de los cuadros de texto permiten cerrar o ocultar la prolongación de la ciudad, o los desplazamientos de aproximación de actividades turísticas que se encuentran en las afueras de Santiago y su reubicación sobre lo que debiera ser un pedazo de ciudad.

Figura 2. Plano turístico de Santiago "Explore-Chile".

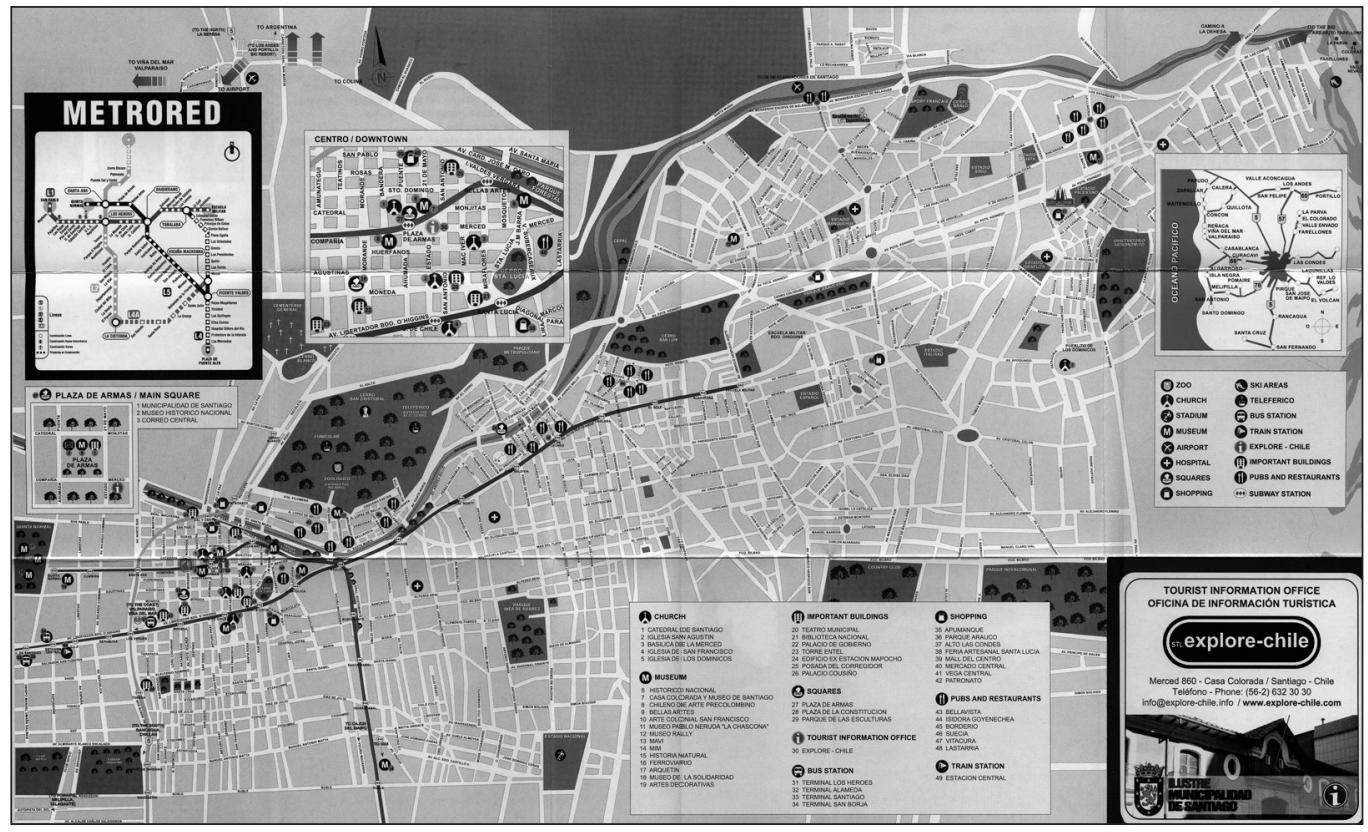

Fuente: Entregado en la oficina de información turística STL Explore-Chile en Merced 860, Casa Colorada (septiembre de 2005).

El resultado de estas operaciones, que podríamos llamar de cirugía estética urbana, es una nueva ciudad llamada también Santiago, de dimensiones mucho más acotadas. Se trata ahora de una ciudad más amigable, posible de recorrer a pie y conocer en pocos días. Pero además, 
la omisión de la ciudad circundante altera las proporciones entre elementos geográficos y paisajísticos (cordillera de Los Andes, río Mapocho y cerro San Cristóbal) y la trama urbana representada, alcanzando un cierto equilibrio y armonía entre lo natural y lo construido. A este propósito sirven también las numerosas áreas verdes que en los planos aparecen como públicas (clubes de golf, clubes deportivos, estadios), pero que bajo la mirada de quien recorre la ciudad quedan ocultas tras infranqueables muros y rejas.

Junto con construir una imagen de ciudad en equilibrio con el medio ambiente, existe un interés en posicionar a Santiago respecto a aquellos valores arquitectónicos y urbanísticos que priman en las grandes metrópolis o "ciudades globales". El Santiago reseñado debe ser un espacio moderno, eficiente, limpio, pero sobre todo un lugar donde prime la movilidad de capitales. El foco de atención en torno a aquellas comunas que presentan los valores de suelo más altos de toda la ciudad, en los lugares donde se concentra la mayor cantidad de proyectos inmobiliarios, claramente facilita la tarea.

Figura 3. Ilustración turística del barrio "Sanhattan".

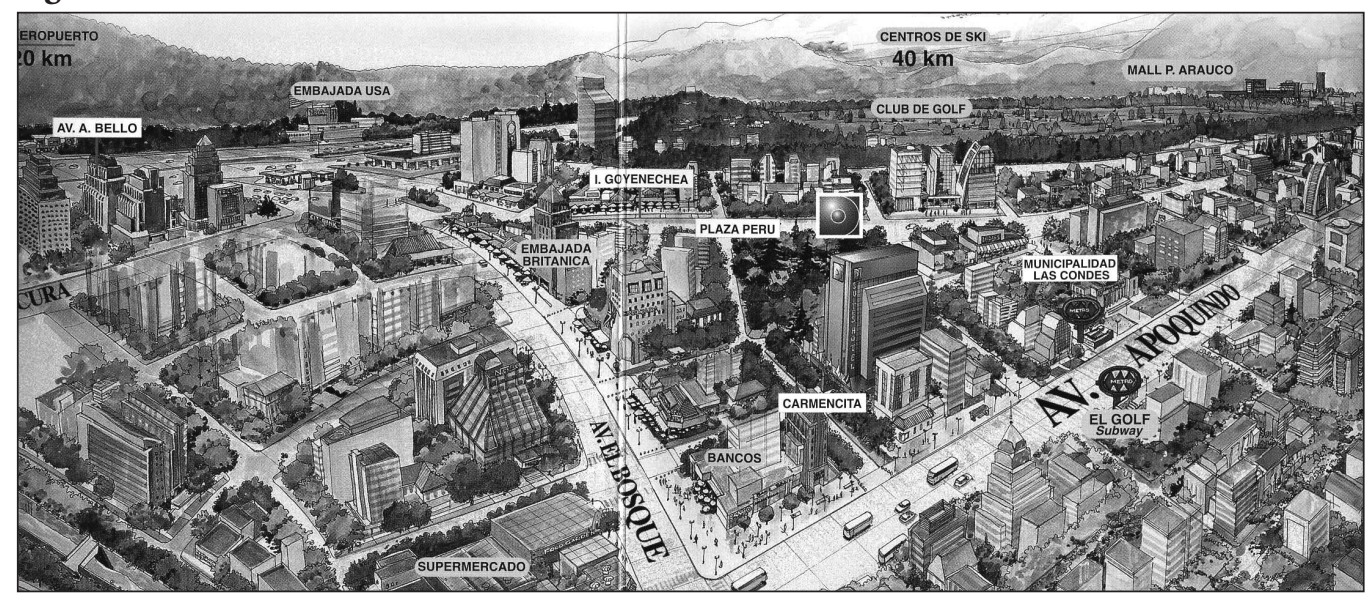

Fuente: Contenido en un tríptico turístico entregado por el Hotel Director, situado en Carmencita 45. (Septiembre de 2005)

En la ilustración de la Figura 3 es posible constatar con claridad esta intención. Además de sugerir una condición de alta conectividad y fluidez, las modernas edificaciones dan fe de un considerable grado de desarrollo de la economía urbana y de una concentración de capitales. Lo que se representa es la ciudad global, genérica, en donde la cordillera se erige como el único elemento que nos recuerda el lugar, mientras todo el resto podría estar en cualquier ciudad del mundo desarrollado.

\section{La región turística}

Vistas las representaciones anteriores, cabe preguntarse ¿Cuál es el verdadero atractivo turístico que puede presentar esta ciudad para sus residentes esporádicos? No fue centro de ningún imperio indígena, tampoco fue sede de un virreinato de la corona española, ni fue un polo importante de desarrollo económico, industrial o cultural durante el siglo XIX o XX, no presenta 
un destacado valor paisajístico y no tiene casino ni playa. Todo indica que, a diferencia de otros centros urbanos, el potencial turístico de Santiago no está en la ciudad misma sino en sus alrededores; en su proyección como centro de una región turística, la región de las "montañas, ciudades y valles" de Chile, tal como aparece promocionado por el Sernatur.

Figura 4. Plano "Metropolitan Region".

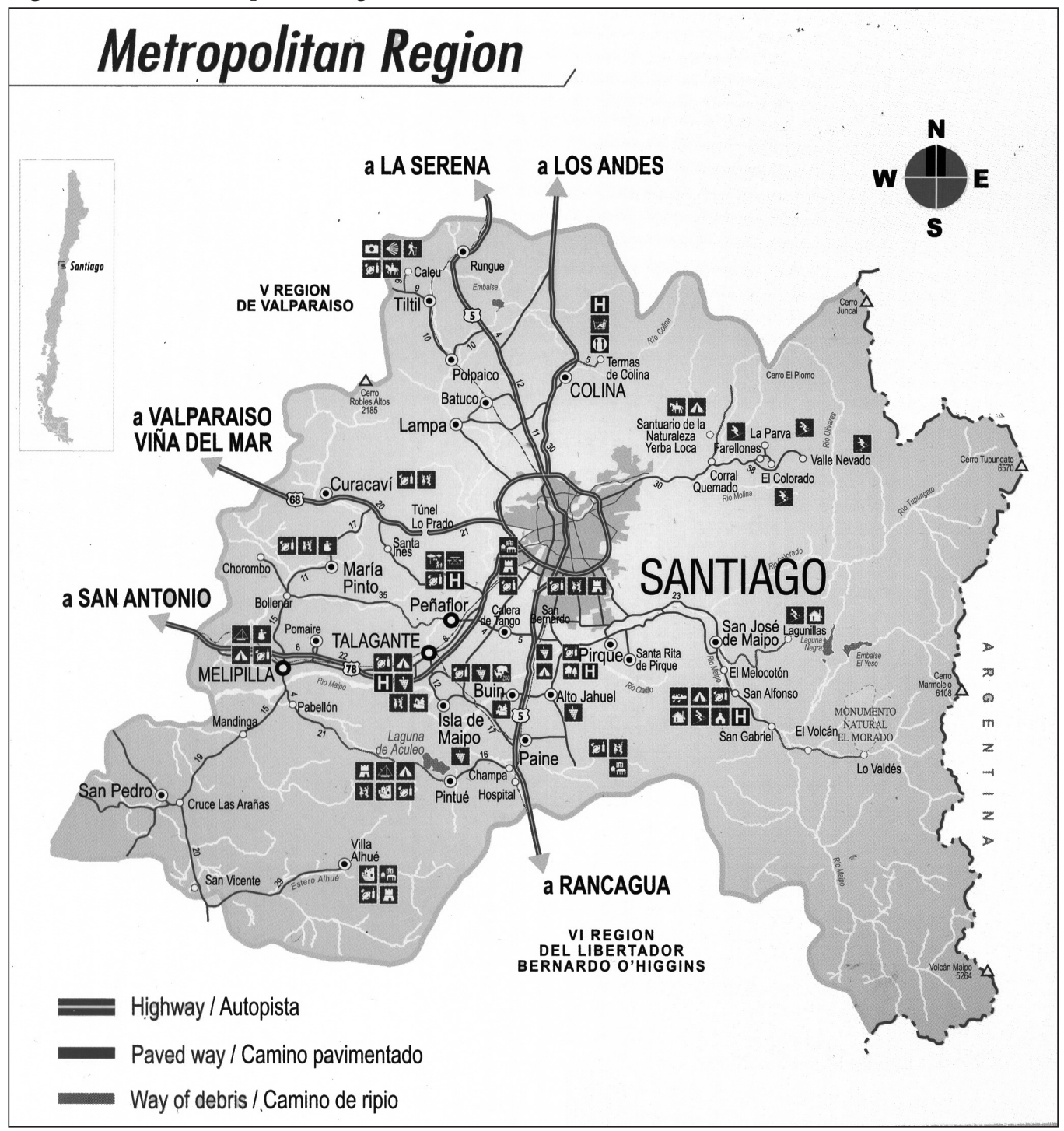

Fuente: Contenido en la guía turística "Santiago Will Surprise you. Tourist Guide, 2007", distribuida por el Servicio Nacional de Turismo.

En este sentido la industria turística busca consolidar a Santiago como centro de operaciones desde donde es posible acceder a variados puntos de interés. Así, la ciudad turística que se ofrece considera además de la pequeńa escala comunal, que constituye generalmente el lugar de alojamiento, de consumo comercial, de transacciones y diversión nocturna, una proyección sobre las potencialidades que puedan brindar los aproximadamente doscientos kilómetros a 
la redonda, distancia determinada por los tiempos de viaje que permiten visitar estos lugares por el día para luego volver a alojarse a la ciudad. Este entendimiento del consumo turístico de los alrededores como parte de la oferta de la ciudad queda claramente consignado en los mapas que se entregan al visitante. Las imágenes que se presentan en la figura 5 son detalles de las indicaciones que comúnmente se encuentran en los bordes de los planos.

Figura 5. Ilustración de los caminos de salida de Santiago en planos turísticos.

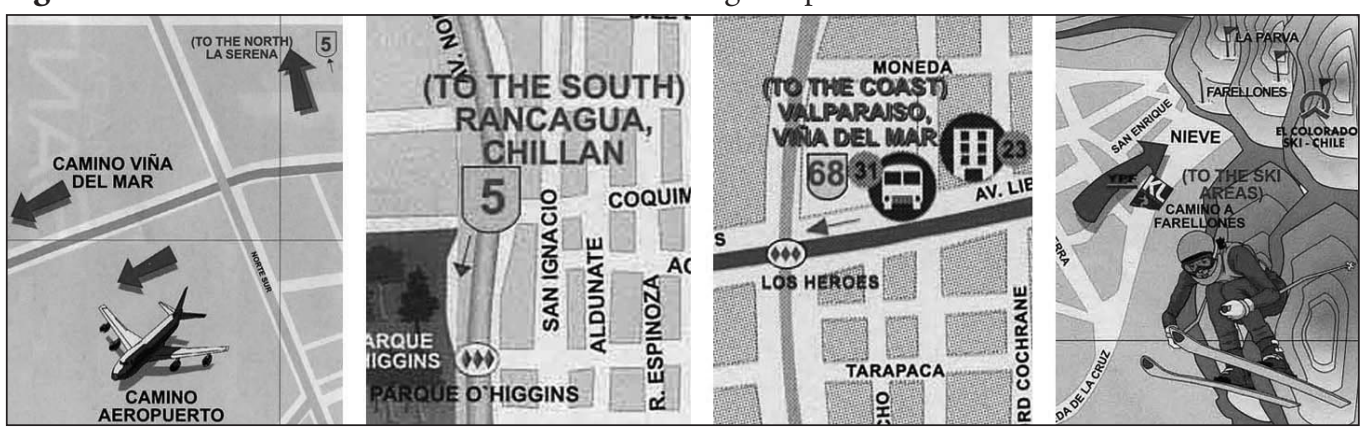

Fuente: De izquierda a derecha, los planos donde aparecen estas ilustraciones son: las dos primeras en el plano "Sernatur" (fig. 6); la tercera en plano "Explore Chile" (fig. 2); y la cuarta en "Freemap. Santiago, Chile", producido por la Unión Internacional de Concierges de Hoteles, Los Andes (2005)

La cordillera, representación obligada en planos y postales que parece constituir el principal hito de la ciudad, es también uno de los destinos predilectos de la actividad turística ofrecida. Los distintos centros de ski, el Cajón del Maipo, las termas, las reservas ecológicas y otras posibilidades de desarrollo como cabalgatas, treking o escalada son los principales espacios de recreación promocionados en esa orientación. Luego hacia la costa destacan especialmente Viña del Mar como balneario principal, Valparaíso como centro histórico patrimonial e Isla Negra como la casa de Pablo Neruda. Por su parte, el sur de Santiago ha experimentado un fuerte auge debido al éxito que ha tenido el agroturismo basado en la producción vinícola, mientras que el norte parece ser el flanco donde la actividad turística es más débil, en la medida en que las ciudades más cercanas, Los Andes y San Felipe, no han sido asociadas aún a un área de desarrollo turístico predominante.

En la medida que gran parte de los atractivos turísticos que presenta la ciudad se encuentran fuera de la ciudad, la conectividad mediante una red de autopistas resalta como principal distintivo de la representación de la ciudad en la escala mayor, que ahora sí coincide con la figura real de la mancha urbana de Santiago.

\section{¿Intereses públicos o intereses privados?}

Tal como mencionábamos anteriormente es frecuente que exista una participación activa de las instituciones y organismos públicos en la industria turística, especialmente en la definición de las políticas de turismo para el país, en la regulación de las industrias del rubro y en la promoción turística nacional e internacional. En el caso de Chile, el Servicio Nacional de Turismo (Sernatur) es el principal organismo público en el rubro, que destaca por ser uno de los principales generadores de material de promoción turística. Para Santiago, existen varias 
guías, folletos y mapas que orientan esta actividad en la ciudad y sus alrededores. Ahora bien, interesa en el marco de esta investigación preguntarse, tal como se hizo frente al material producido desde el sector privado, por cuál es la imagen de Santiago que se construye.

En la figura 6 se observa la representación más completa de la ciudad de Santiago entregada por el Sernatur, en una escala donde aún aparecen las calles. No se requiere mayor atención para comprobar que las similitudes con los planos generados desde sector privado son numerosas. De Santiago sólo se presenta un fragmento conformado por el centro fundacional y el cono de alta renta. Existe una clara constricción del primero en relación a las comunas de Providencia y Las Condes, preferencia que se subraya mediante la ubicación del centro del mapa justo en Tobalaba con Providencia. Una vez más, las acotadas dimensiones de la ciudad turística acentúan la armonía con el medio ambiente y el verde como estrategia gráfica simula espacios públicos allí donde no los hay. Pero probablemente lo más notable es que la imagen de ciudad que se construye no sólo omite a gran parte de la ciudad restante, sino que, tal como lo veíamos en otros planos, la continuidad y proyección de la trama urbana desde las comunas retratadas más fielmente se esconde tras la representación de grandes paños de terreno con dimensiones rurales.

Figura 6. Plano turístico de Santiago "Sernatur".

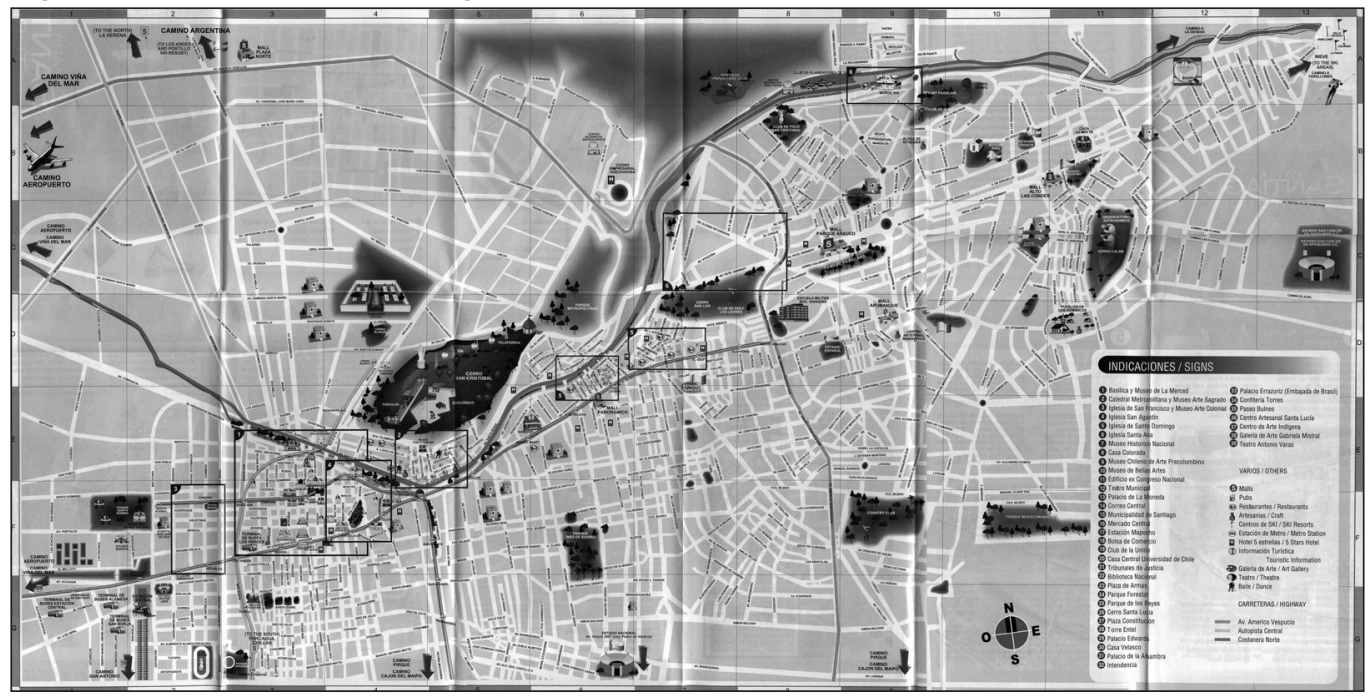

Fuente: Plano plegable distribuido por el Servicio Nacional de Turismo en sus oficinas, Municipalidades y principales hoteles de cuatro y cinco estrellas de la capital (2005)

Pero no todo es similitud, también se observan importantes diferencias que sugieren tímidamente algunas de las motivaciones tras el carácter público del organismo generador de la imagen. A diferencia de los mapas anteriores, éste expande los límites de la ciudad turística, aunque sin perder el encuadre general, en prácticamente todas las direcciones.

Por el reverso de este mapa aparece información detallada y planos en una escala más pequeña sobre algunos sectores de interés particular. En las figuras 7 y 8 se han seleccionado aquellos lugares que se encuentran al interior del radio urbano. Entre los sectores representados, 
destacan tres comunas frecuentemente omitidas de los mapas turísticos: La Florida, Maipú y Peñalolén. El mensaje parece ser claro: Sernatur como organismo público orientado a promover el bien común busca ampliar hacia nuevos lugares y nuevas personas los beneficios de la actividad turística.

Figuras 7 y 8. Destinos de interés turísticos señalados por Sernatur al interior del radio urbano de Santiago.

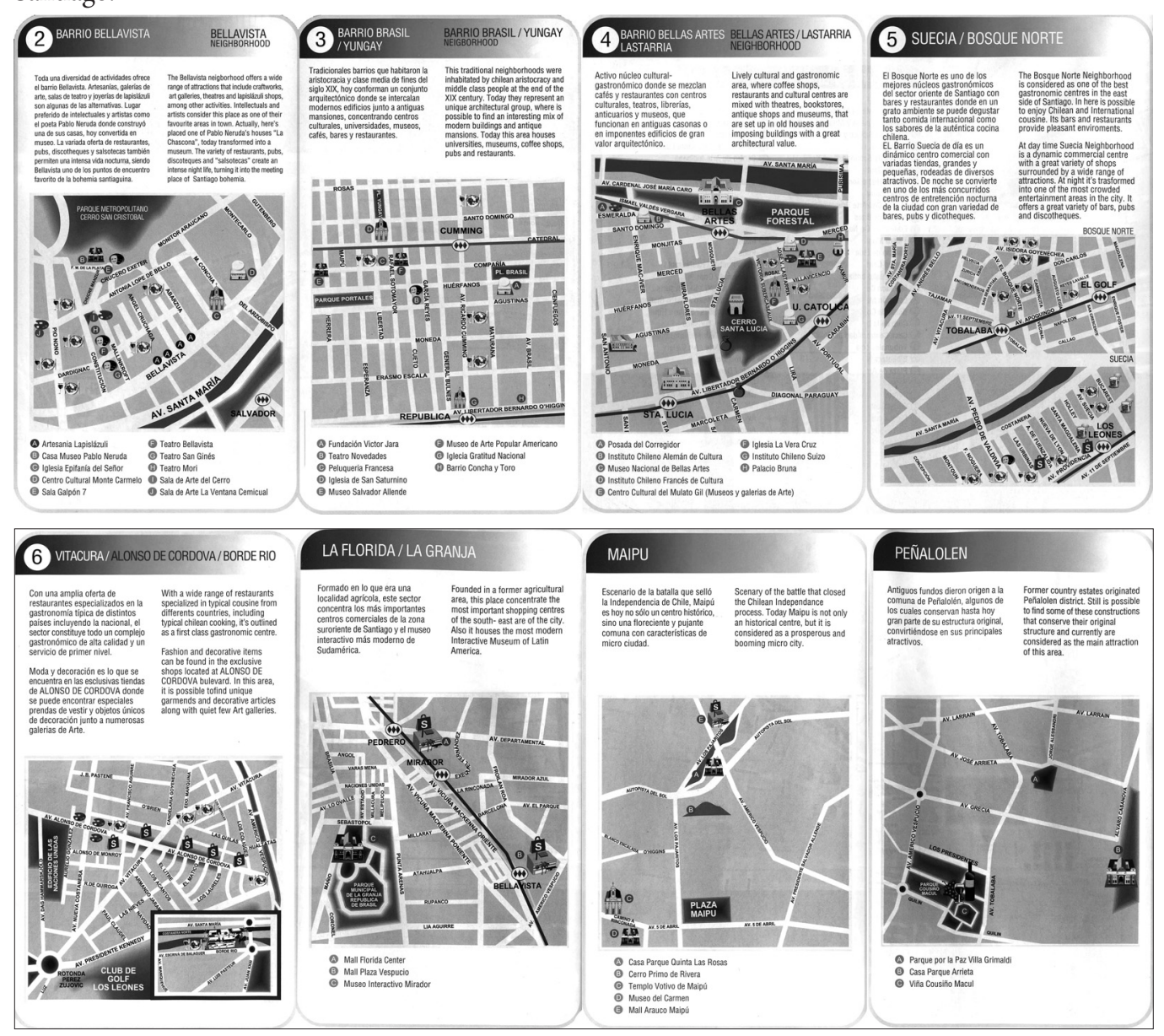

Fuente: Reverso del plano del plano turístico de Santiago "Sernatur" (figura 6).

No obstante, estos intentos por incluir nuevos espacios y personas en la promoción turística de Santiago quedan en el terreno de las intenciones cuando se analiza con mayor cuidado qué es lo que se está representando y cómo se está haciendo. Para ilustrar esta situación se han seleccionado dos de los textos que acompañan a estas representaciones; primero el del barrio Bellavista y luego el de Maipú.

Toda una diversidad de actividades ofrece el barrio Bellavista. Artesanías, galerías de arte, salas de teatro y joyerías de lapislázuli son algunas de las alternativas. Lugar preferido de intelectuales y artistas como el poeta Pablo Neruda, que construyó en él una de sus casas, hoy convertida 
en museo. La variada oferta de restaurantes, pubs, discotheques y salsotecas también permiten una intensa vida nocturna, siendo Bellavista uno de los puntos de encuentro favorito de la bohemia santiaguina.

Escenario de la batalla que selló la Independencia de Chile, Maipú es hoy no sólo un centro histórico, sino una floreciente y pujante comuna con características de micro ciudad.

Si bien las diferencias son numerosas, desde la extensión de texto que se le dedica hasta la diversidad de atractivos que se les atribuyen, la principal divergencia que condena las potencialidades turísticas de la comuna de Maipú es que no tiene actividades asociadas al lugar. Algo similar sucede con las otras dos comunas: Mientras en Peñalolén también se hace referencia al pasado histórico y a la conservación de parte de esta estructura agrícola y su arquitectura, sin ningún tipo de información de cómo eso se transforma en experiencia turística, en La Florida, a parte del Museo Interactivo Mirador, el énfasis en la actividad comercial y en los mall claramente no constituye una ventaja comparativa de esa comuna sobre otras mucho más representadas y referenciadas como Providencia y Las Condes.

Luego, es interesante ver cómo la representación gráfica del lugar, al menos en los casos de Peñalolén y Maipú, tampoco aporta a su promoción turística. Comparado con las otras imágenes, estos destinos constituyen verdaderos descampados, que no guardan ninguna relación con la estructura urbana real. Resulta incluso irrisorio y vergonzoso leer la descripción de Maipú como "una pujante comuna con características de micro ciudad" y luego observar el modo en que ha sido representada.

\section{Consideraciones finales}

Peñalolén, Maipú y La Florida, como la gran mayoría de las comunas de Santiago que no pertenecen a aquel polígono conformado por el centro y el cono de alta renta, están ciertamente muy lejos de poder participar de los beneficios que conlleva el desarrollo de la actividad turística. Si bien el Sernatur considera en su agenda diversificar la oferta de espacios turísticos en la ciudad, las estrategias escogidas para cumplir con este fin, al menos desde el ámbito de la promoción y la difusión, son escasas y visiblemente infructuosas. En cambio, las labores de promoción desarrolladas desde este organismo, parecen ser mucho más y exitosas cuando se trata de difundir nuevos lugares de interés al interior de la zona turística consolidada.

Todo indica que existe una confluencia, o probablemente habría que hablar de un acuerdo, entre los intereses públicos y los privados en la construcción de una imagen de ciudad que omite y excluye deliberadamente a la gran mayoría de sus habitantes de los beneficios que trae esta actividad. Ante el rol activo asumido por el estado en este fenómeno de exclusión, resulta conveniente atender algunas de las conclusiones a las que llega Briavel Holcomb (1999), luego de estudiar el marketing urbano como potenciador del turismo y el rol que le compete a las instituciones públicas en la promoción de ciudades.

“(...) Los objetivos de las políticas futuras debieran minimizar el gasto público en la promoción que beneficia principalmente a intereses privados, para asegurarse que las imágenes proyectadas 
sean inclusivas de las distintas comunidades y fidedignas en su representación, y distribuir más equitativamente los costos y beneficios del turismo al interior de la ciudad".

La definición de la actividad turística en relación a esta fractura urbana nos lleva a replantear algunas de las últimas reflexiones que se están llevando a cabo entre quienes se han dedicado a estudiar las consecuencias del fenómeno turístico sobre la ciudad. Estos estudios recientes, superando la lectura posmoderna del turismo urbano desde el enclave o la ciudad temática, proponen una mirada optimista sobre la actividad turística que tendría lugar a partir de una experiencia turística urbana que reconoce la diversidad social y cultural de las ciudades.

Sin embargo, esta nueva mirada desconoce que es común a la promoción turística de las ciudades funcionar siempre desde una lógica de inclusión-exclusión/omisión. Las personas que visitan una burbuja turística saben que fuera de los límites de ésta hay ciudad, sin embargo quienes pasean por la ciudad demarcada turísticamente no siempre saben que se extiende más allá de lo que aparece en el plano que se les ha entregado.

\section{Referencias bibliográficas}

AlSayyad, N. (2001). Global norms and urban forms in the age of tourism: manufacturing heritage, consuming tradition. En N. AlSayyad (Ed.), Consuming tradition, manufacturing heritage. Global norms and urban forms in the age of tourism (1a. ed., pp.1-33). New York: Routledge, Taylor \& Francis Group.

Fermandois, J. (2000). El fin del viaje: ¿una pérdida irrecuperable? Estudios Públicos, 77, 341-355.

Holcomb, B. (1999). Marketing cities for tourism. En D. Judo \& S. Fainstein (Ed.), The tourist city (1a. ed., pp. 54-70). New Haven: Yale University Press.

Judd, D. (2003). El turismo urbano y la geografía de la ciudad. EURE, 29, 87, 51-62.

La Segunda (2006, 26 de diciembre). Turismo en Chile aumentará más de un 11 por ciento este año.

Sernatur, Gobierno de Chile (2001). Perfil del turista en Chile año 2000. Resumen gráfico. Santiago: Servicio Nacional de Turismo, Chile - Estadísticas de Turismo

Sernatur, Gobierno de Chile (2006). Turismo. Informe anual 2005. Santiago: Servicio Nacional de Turismo, Las Estadísticas de Chile. 